\title{
Contributing to a Global Conversation on Mixed Method Research
}

\section{Dr. Elizabeth G. Creamer ${ }^{1}$}

As president (2018-2019) of the Mixed Methods International Research Association (MMIRA), I write to extend a warm endorsement for this special call for articles devoted to mixed methods research approaches by the Revista de Enfermagem da Universidade Federal de Santa Maria (REUFSM). The special issue joins an exciting initiative, also launched by associate editor, Dr. José Luís Santos from the Universidade Federal de Santa Catarina, to formalize arrangements for a Latin American chapter of MMIRA and to organize workshops and a conference to reach out to its diverse constituencies. These types of activities contribute to global exchanges about mixed methods research and the future directions of the organization.

The activities of the Mixed Methods International Research Association Latin American Chapter (MMIRA-LA) come at a propitious time in the development of the organization. Formally organized barely seven years ago and now about 650-member strong, MMIRA is unique in its ambition to promote mixed methods research approaches worldwide. Only its third, the 2018 MMIRA global conference in Vienna, drew delegates from almost 40 countries. It is anticipated that issues related to contribution of chapters (and affiliates) to MMIRA will be foregrounded in the next global conference in 2021 . Here we will be discussing the politics of location and the ways that local, regional, and national social and economic forces shape a research agenda, funding opportunities, access to infrastructure, expertise, resources, and to colleagues who share an enthusiasm for mixed methods.

\footnotetext{
${ }^{1}$ Professor Emerita, School of Education, Virginia Polytechnic Institute and State University. Blacksburg, VA, USA ORCID: 0000-002-6897-0869 E-mail: creamere@vt.edu
} 
MMIRA provides members access to a range of different types of professional development opportunities that are delivered through different platforms. This includes face-toface interactions at regional conferences and a bi-annual global conference. For example, regional conferences in 2019 were hosted in Trinidad by the Caribbean chapter, in New Zealand by a chapter that is forming to represent the Australasia region, and in Japan by an affiliate that has been active since about the time in 2013 when MMIRA was formed. Professional development opportunities include a webinar series and course materials offered online. It is anticipated that the first phase of a new series of more than two-dozen on-line modules by many of the leading figures in the field will be available to members in fall 2019. Members can enhance their expertise by accessing videos of now nearly 30 webinars through the organizations' webpage (https://mmira.wildapricot.org). Membership in the organization provides ready access to a diverse network of researchers worldwide, but also contributes to furthering its mission to advance mixed methods worldwide.

One of the most common reactions when first encountering a group of mixed methods folks is to express surprise at the diversity of perspectives. Diverse does not mean incompatible. This is not, nor should it be expected to be, a community with monolithic views. Nor is it one that finds common ground through the practice of a prescribed set of procedures. Becoming aware of the diversity of perspectives of this creative group of scholars is a first step to developing an appreciation for the vibrancy and dynamism of the methodology.

\section{Corresponding Author}

Name: Dr. Elizabeth G. Creamer

E-mail: creamere@vt.edu

Address: Virginia Polytechnic Institute and State University

Zip code: 24060

\section{How to cite this article}

Creamer EG. Contributing to a Global Conversation on Mixed Method Research. Rev. Enferm. UFSM. 2019 [Acess at: Year Month Day];vo.9 (Esp)1 e1: 1-2. DOI:https://doi.org/10.5902/2179769239753 